\title{
Sandu Frunză, Comunicare și consiliere filosofică. Editura Eikon, Colecția Universitas, Seria Filosofie, Cluj-Napoca, 2019.
}

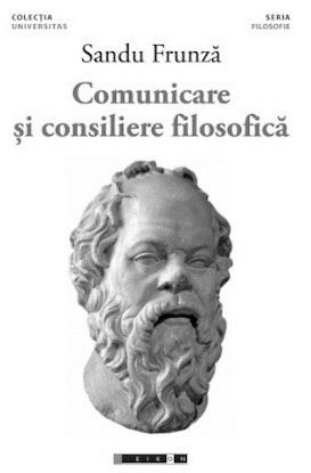

Profesorul universitar dr. Sandu Frunză, din cadrul Universității Babeș-Bolyai, este unul dintre filosofii ce au adus un real aport dialogului între teologie și filosofie, întrucât una din lucrările sale fundamentatele îl are în centru pe Părintele Dumitru Stăniloae „O antropologie mistică. Introducere în gândirea Părintelui Stăniloae (1996) și Experiența religioasă în gândirea lui Dumitru Stăniloae. O etică relațională (2001) reprezintă parte din cele mai reprezentative lucrări ale sale, la care se adaugă Fundamentalismul religios și noul conflict al ideologiilor publicată în 2003 şi reeditată în 2015 într-o ediţie actualizată și mult extinsă. Competentele sale vaste includ arii din filosofia religiilor, sociologia religiei, antropologie, științele comunicării, științte politice etc.

Vă propunem spre lecturare o carte binevenită (recent tradusă și în limba engleză - Philosophical counseling and Communication apărută la editura Presa Universitară Clujeană, Cluj-Napoca, 2019) menită să popularizeze un domeniu relativ nou de cercetare, însă care e cât se poate de vechi ca formă, sau ca idee prin înțelegerea filosofiei, ca metodă de consiliere, de terapie pragmatică venită din străfundurile ancestrale ale civilizaţiei umane, programate tocmai pentru omul postmodern, omul recent (așa cum îl definește H. R. Patapievici), concluzionând argumentaţia că filosofia nu e doar un exerciţiu speculativ, ci așa cum ne propune Domnul Profesor Sandu, e arta de a trăi . De bună seamă, teza aceasta este destul de recent întâlnită la Pierre Hadot (vezi Ce este Filosofia antică?, unde se postulează ideea că filosofia poate genera anumite exerciții spirituale, preluate de la antici și recuperate prin Ignațiu de Loyola, ulterior).

Tema recurentă propusă de autor este axată pe concepția că filosofia nu este destinată doar elitelor, ci mai cu seamă ea generează 
școli de gândire populare ce sunt parte definitorie a ceea ce numim în tendința reducționistă pop culture. Această restituţie a terapiei, respectiv a consilierii spirituale, este propusă de autor pornind de la analiza cadrelor lumii actuale, postmoderne, în care metodele și explozia informațională generează tehnologii, respectiv metode noi de decriptare a lumii, respectiv a Ființei ca arhetip al ființei umane (p. 10).

Rolul filosofului este în acest cadru unul esențial, prin actul de anarhie, respectiv protest împotriva lumii, de unde se nasc relaţiile conflictuale între profesii etc. Așadar, el afirmă: „Filosofia nu revine ca o reacție impotriva tehnologizării, ea este mai degrabă o formă de integrare a acesteia în viața ta. Tocmai de aceea, reîntoarcerea la filosofie nu e o consecință a nevoii de restaurare a unei umanități ce s-a înstrăinat de condiția sa, ci o cerință a situării omului în dezvoltarea $s a$ "(p.9). Lucrarea de față este un veritabil exemplu de interdisciplinaritate, întrucât autorul jonglează cu precizie autori consacrați precum Marinoff, Emmy vad Deurzen, Aurel Codoban ș.a., ce întăresc teza că această disciplină nu este un surogat, sau că aceasta nu exercită o hegemonie asupra religiosului sau a spiritualității. Este adus în discuție Profesorul Aurel Codoban, pe care autorul îl plasează la loc de cinste în arta sa argumentativă care postulează faptul că: ,,(..) practica filosofică constituie crearea unei ontologii a detaliului în care elementul fundamental al definirii condiției umane nu mai este raționalitatea, ci dorința"(p.14). Ideea extinsă exhaustiv de către Domnul Sandu atinge diferite zone ale modernității supuse unei vrăjiri a dezirabilului exploatat consumist, care se întrupează în orizontul ființei umane, care sacralizează și demonizează deopotrivă. Apoi, analiza cade inevitabil în limbaj care devine spațiul de luptă care naște hermeneutica culturii erotice (dezirabile) prin problematizare și întoarcerea la valorile spirituale (p.17). Se menține în acest sens precauția filosofului de a evita concluziile, care pot anihila actul de dorință, sau pot instaura mortificarea filosofiei. Teza aceasta este confirmată de către filosoful și terapeutul Virgil Ciomoș care afirmă: „,...) dacă nu toți oamenii de cultură au început cu filosofia, mai toți au sfârșit printr-o reflecție filosofică asupra propriei lor vocații. Fericiții încep cu filosofia, fericiți cei ce sfârșesc cu ea" (p.26). Această viziune complementară a practicii filosofice cu teoria este rezolvată nu de o separație sau fractură, ci mai 
degrabă de potențarea vocației comune a însăși filosofiei (Marinoff, p.37) prin creativitate. Este continuată dezbaterea filosofică într-o manieră antropomorfizată, a jocului de duşmănie versus prietenie între disciplinele conexe spiritului, respectiv psihologia și psihiatria, însă filosofia se diferențiază datorită rolului său metafizic (p.41). Schematizarea continuă cu propunerea lui Marinoff ce concepe la nivel vizual, un triunghi (o triadă) prin care se: „reprezintă consilierea filosofică în cadrul unei relații trioadice, caracterizată prin prezența biologicului, afectul și gândirea ocupă fiecare un vârf al triunghiului."'(p.57). Curgerea acestor concepte se realizează gradual într-o descărcare aproape firească, la nivelul filosofic, prin ceea ce, de pildă, teologia numește misterul dialogului, văzut în acest context ca metodă de terapie, urmând paternul antic al arhicunoscutelor dialoguri.

Autorul afirmă că scopul acestor dialoguri îl reprezintă motivarea existențială. Este, de altfel, foarte clar precizat că incidența acestor acțiuni terapeutice nu se substituie formelor patologice sau terapiei pastorale (p.68-69). Dacă anterior se făcea precizare la problema limbajului cu limitele impuse ale acestuia, acum autorul aduce în discuție problema imaginarului religios și al științei, aducând-o în discuție pe Emmy van Deurzen, care clasifică necesitatea filosofiei în actul de demitologizare în care uneori religia poate cădea în misticism și mitologizare. Așadar, scopul consilierii filosofice nu este acela de a ne plasa într-o dispută absolut mecanicistă (stearpă) cu religia, ci acela de a ne îndrepta maieutic către împăcarea cu sinele nostru şi către redescoperirea spiritualității, deși Profesoara Mihaela Frunză avertizează faptul că se poate crea o confuzie conceptuală între ideologie și religie (ideologizarea religiei). Aici intervine axiologia (etică) între ideea de consiliere și conflictul ideologic, nu în sensul de a înlocui ideologiile, ci de a le clarifica (p.107). Contemporaneitatea ne oferă șansa de a experimenta noi tehnologii, noi abordări ale postumanismului care nu fac altceva decât să potențeze în ființa umană noi intensități ale dorinței (sacre, prin fiatul divin), dar care pot să fie colportate şi în maniera unui stil de viaţă adictiv, consumist ce să necesite clarificări de natură filosofică ori conceptuală. Aici filosoful Aurel Codoban postulează necesarul de recuperare a raţionalităţii filosofice pentru a scoate din tăcere divinitatea. Acest fapt generează o 
stare de nostalgie paradisiacă a iubirii, ca virtute ancestrală, care trebuie să interacționeze cu complexitatea comunicațională a noii filosofii a corectitudinii politice (p.126), prin dialog și toleranţă, dar dacă e privată de discernământul filosofic, Aurel Codoban avertizează, aceasta poate fi fetișizată.

Putem cu ușurință observa faptul că sunt respectate normele eticii spirituale prin descrierea pe care autorul o plasează, prin enunțarea repetată a tensiunilor spirituale camuflate, prin gradualitatea dorințelor care pot decădea în afecte (psiho-filosofice). Insumarea acestui demers analitic ne conduce, în viziunea filosofului Sandu Frunză, la o regresie la esența corporalităţii noastre care, în viziunea Părintelui Dumitru Stăniloae, transcende participativ relația personală spre alteritate al raportării totale a spiritualizării, fiind esența simbolismului creștin (p.138-139). Autorul este ferm convins de realitatea spirituală asupra sacralității pe care o ideologizează, aducând-1 în discuție pe Rudolf Otto care afirmă: ,experiența sacrului e sub un dublu aspect (...) aduce o trăire a fascinației extraordinare în fața măreției și a infinitului spiritului, ce se revarsă în experiența trăită, iar pe de altă parte e neputința trăită sub semnul fricii de a nu pierde în totalitate într-o experiență a vieții infinite" (p.148).

Concluzionând, lucrarea de față a distinsului Profesor Universitar Sandu Frunză e un excepțional tratat de înțelegere a postmodernității din perspectiva analizei spiritului contemporan care e supus unei fenomenologii a dorinței, care naște, potențează ori lovește politic filosofia, ca act reflexiv (al logosității) de participare asupra cosmosului a întregii existențe umane. Îndemnul spre o apologie a consilierii filosofice, care e în complementaritate cu terapia psihologică ori cu arta pastorală, fac parte din ceea ce numește autorul, în deplină cunoștință de cauză, parafrazându-l pe Immanuel Kant (p.208), doctrina înțelepciunii, a cărui apologet este și Profesorul Sandu Frunză. Vă îndemnăm la o rodnică lectură, deopotrivă filosofică și spirituală.

Pr. drd. Emanuel CĂȘVEAN

Facultatea de Teologie Ortodoxă, Universitatea Babeș-Bolyai din Cluj-Napoca 